\title{
Fine Structure of Spore Germination in Actinomycetes
}

\author{
BY G. P. SHARPLES AND S. T. WILLIAMS \\ Botany Department, University of Liverpool, Liverpool L69 $3 B X$
}

(Received 2 April 1976)

\begin{abstract}
SUMMARY
Ultrastructural changes during the germination of spores of the actinomycetes Microbispora rosea, Microellobosporia flavea, Micromonospora melanosporea, Micropolyspora faeni and Streptomyces ostreogriseus were studied. The thickness of mature spore walls and the number of layers distinguishable in them varied between species. In all cases, swelling of spores occurred during germination and existing wall layers either stretched or ruptured.

In Microellobosporia flavea, the germ-tube wall arose from a layer newly synthesized during germination. Germ-tube walls in Microbispora rosea and Micromonospora melanosporea arose from inner layers of the wall which were distinguishable in dormant spores. In Micropolyspora faeni and Streptomyces ostreogriseus the germ-tube wall was formed from the inner layer of the spore wall which separated from the outer layer during germination. These patterns resembled those previously observed in fungal spores. There was no correlation between the behaviour of wall layers during germination and the wall composition of the genera studied.
\end{abstract}

\section{INTRODUCTION}

Studies of the fine structure of actinomycete spores during germination have been confined to the genera Streptomyces (Hagedorn, 1960; Glauert \& Hopwood, 196I; Mach, I965; Bradley \& Ritzi, I968; Kalakoutskii \& Pouzharitskaya, 1973) and Thermoactinomyces (Dorokhova et al., I968; Lacey \& Vince, 1971; Kalakoutskii \& Agre, 1973). The latter genus forms endospores which behave in a similar way to those of Bacillus, a new wall layer being synthesized inside the cortex of the spore and extending to form the germ-tube wall. In the Streptomyces species studied, the spores had a two-layered wall and the inner one extended to form the germ-tube wall. It is not clear if this layer is newly synthesized during germination or if it is formed by reorganization of wall material existing in the dormant spore.

Ultrastructural changes during the germination of fungal spores have been studied more extensively. Most fungi fall into one of two groups: (i) those in which the germ-tube wall is formed from a layer which is synthesized de novo within the existing spore wall; (ii) those in which the germ-tube wall is formed by extension of a wall layer already present in the dormant spore (Bartnicki-Garcia, I968). Some conflicting results have been obtained and closely related species have been reported to fall into different groups (Khan, 1975). This may be partly due to the use of different fixatives, potassium permanganate giving inferior results to those obtained with osmium tetroxide or aldehydes (Border \& Trinci, 1970; Gull \& Trinci, 1971). Marked changes in spore wall layers can also be induced by hydration during specimen preparation (Florance, Denison \& Allen, 1972).

In the present study, ultrastructural changes during germination of spores of various actinomycete genera were followed. Results were compared with those previously obtained with fungi. 
Table I. Origin and cell-wall composition of organisms studied

\begin{tabular}{llc}
\multicolumn{1}{c}{$\begin{array}{c}\text { Organism } \\
\text { Microbispora rosea }\end{array}$} & $\begin{array}{l}\text { Origin } \\
\text { Botany Dept, Liverpool } \\
\text { University (E6) }\end{array}$ & $\begin{array}{c}\text { type of genus* } \\
\text { Type III }\end{array}$ \\
Microellobosporia flavea & $\begin{array}{l}\text { Institute of Microbiology, } \\
\text { Rutgers University, New } \\
\text { Jersey, U.S.A. (IMRU3858) }\end{array}$ & Type I \\
Micromonospora melanosporea & $\begin{array}{l}\text { Institute of Plant Pathology, } \\
\text { Milan, Italy (583) } \\
\text { Dept of Biological Sciences, } \\
\text { Bradford University (cUB407) }\end{array}$ & Type II \\
Micropolyspora faeni & $\begin{array}{l}\text { International Streptomyces } \\
\text { Project (ISP55I I) }\end{array}$ & Type I \\
Streptomyces ostreogriseus & * From Lechevalier \& Lechevalier (1970). & \\
&
\end{tabular}

\section{METHODS}

Strains and cultivation conditions. Details of the organisms used are given in Table I. Spores of Micropolyspora faeni were produced by growing cultures on plates of nutrient agar (Oxoid) at $45^{\circ} \mathrm{C}$ for 2 days. All other strains were grown on oatmeal agar at $25^{\circ} \mathrm{C}$ for 2 to 3 weeks.

Spores were harvested from the plate cultures, washed twice in sterile distilled water and transferred to Io $\mathrm{ml}$ nutrient broth (Difco) in test-tubes. These were incubated for 24 to $48 \mathrm{~h}$ at $25^{\circ} \mathrm{C}\left(45^{\circ} \mathrm{C}\right.$ for Micropolyspora faeni).

Ultra-thin sections. Spores incubated in nutrient broth and unincubated spores washed in sterile water were examined. The latter were used to determine the structure of mature, ungerminated spores. The spores were sedimented by centrifuging, washed twice in veronal acetate buffer $(\mathrm{pH} 6 \cdot \mathrm{I})$, fixed in $1 \%(\mathrm{w} / \mathrm{v})$ osmium tetroxide in buffer for $16 \mathrm{~h}$ at room temperature and then washed in $0.5 \%(\mathrm{w} / \mathrm{v})$ uranyl acetate solution for $3 \mathrm{~h}$.

Fixed spores were resuspended in $0.03 \mathrm{ml} 2 \%(\mathrm{w} / \mathrm{v})$ molten agar at $45^{\circ} \mathrm{C}$ and mixed on a slide. When the agar drop had set, small blocks were cut out and dehydrated by passage through a graded series of ethanol-water mixtures. They were then embedded in a low viscosity resin (Spurr, 1969) as recommended by Gull \& Trinci (1971), and sectioned. Sections were picked up on formvar-coated grids and stained with $2 \%(\mathrm{w} / \mathrm{v})$ uranyl acetate for $30 \mathrm{~min}$ and with lead citrate (Reynolds, 1963) for 5 to $15 \mathrm{~min}$. After staining, sections were washed for $30 \mathrm{~s}$ in distilled water and left to dry in air.

Specimens were examined using an EM6B electron microscope (A.E.I.) at $60 \mathrm{kV}$. Measurements were carried out on prints using a calibrated magnifier.

\section{RESULTS}

\section{Spore germination in Streptomyces ostreogriseus}

Mature spores had a mean diameter of $0.65 \mu \mathrm{m}$, and electron-dense contents in which it was difficult to distinguish nuclear material or ribosomal granules (Fig. I). Their walls were 50 to $60 \mathrm{~nm}$ thick, increasing to 100 to $200 \mathrm{~nm}$ at the poles where intersporal pads had 
Table 2. Changes in dimensions of spores and their walls during germination

\begin{tabular}{|c|c|c|c|c|c|}
\hline \multirow[b]{3}{*}{ Organism } & \multirow{2}{*}{\multicolumn{2}{|c|}{$\begin{array}{c}\text { Diameter of spores } \\
(\mu \mathrm{m})\end{array}$}} & \multicolumn{3}{|c|}{ Wall thickness (nm) } \\
\hline & & & \multirow{2}{*}{ Dormant } & \multicolumn{2}{|c|}{ Germinating } \\
\hline & Dormant & Germinating & & Observed & $\underbrace{}_{\text {Calculated* }}$. \\
\hline ayces ostreogriseus & 0.65 & 0.8 & $50-60$ & $30-40$ & $37 \cdot 5-46 \cdot 2$ \\
\hline lyspora faeni & $I \cdot 00$ & $I \cdot 2$ & $70-100$ & $40-80$ & $50 \cdot 4-72 \cdot 0$ \\
\hline pora rasea & $1 \cdot 00$ & $1 \cdot 5$ & $23-26$ & $8-15 \dagger$ & $10.8-12.2 \dagger$ \\
\hline nospora melanosporea & 0.6 & $I \cdot I$ & $30-40$ & $10-16 \dagger$ & I6.5-22.0† \\
\hline obospora flavea & $1 \cdot 7 \times 2 \cdot 2$ & $\mathrm{I} .8 \times 3.0$ & $50-80$ & $70-100$ & - \\
\hline
\end{tabular}

developed, and consisted of a single layer with an outer electron-dense zone (I3-26 nm) and an inner lighter zone.

During germination, the spore diameter increased to $0.8 \mu \mathrm{m}$, giving a $23 \%$ increase in surface area. If there was no synthesis of wall material during this process, the existing wall would be stretched and hence become thinner. The theoretical thickness of the stretched wall can be calculated (Gull \& Trinci, 197I) from the equation $t_{\mathrm{s}}=t_{\mathrm{d}} \times(\mathrm{I00} / S)$, in which $t_{\mathrm{s}}$ is the thickness of the wall after swelling, $t_{\mathrm{d}}$ is the thickness of the dormant spore wall, and $S$ is the surface area of the swollen spore expressed as a percentage of the dormant spore surface area. The calculated value for the thickness of the swollen spore wall was close to that observed (Table 2), indicating that synthesis of new wall material had not occurred during swelling.

Initially, the walls of swollen spores were almost homogeneous but eventually became clearly differentiated into an outer and inner layer, each Io to $\mathrm{I} 2 \mathrm{~nm}$ in thickness (Fig. 2). On germination, the outer one ruptured at the point of emergence while the inner layer developed to form the germ-tube wall (Figs. 3 and 4). Remnants of the fibrous sheath in which the spores formed persisted around swollen spores (Fig. 2) but were absent from the germ-tube surface. Nuclear material and ribosomal particles were clearly visible in germinating spores and mesosomes were common (Fig. 4).

\section{Spore germination in Micropolyspora faeni}

Mature spores had a mean diameter of $\mathrm{I} \cdot 0 \mu \mathrm{m}$, were partially enclosed in a sheath, and had electron-dense contents. The walls were quite thick ( 70 to $100 \mathrm{~nm}$ ) and consisted of a faint outer zone (Io to $20 \mathrm{~nm}$ ) and an inner less dense zone (60 to $80 \mathrm{~nm}$ ) (Fig. 5).

The diameter of spores increased to $\mathrm{I}$ to $2 \mu \mathrm{m}$ during germination, giving an increase of $39 \%$ in surface area. The thickness of the wall decreased to 40 to $80 \mathrm{~nm}$ which was close to the value calculated assuming no synthesis (Table 2). At this stage the appearance of the spore wall was unchanged except for occasional thinner points and breaks in the sheath, possibly representing points of eventual germ-tube emergence (Fig. 6). Where the germtube emerged, central cleavage of the wall produced two layers, an inner one continuous with the germ-tube wall and an outer one which ruptured (Fig. 7). Remains of the sheath were still visible but it played no part in the germination process. Nuclear material and ribosomal particles were clearly visible in germinating spores. 


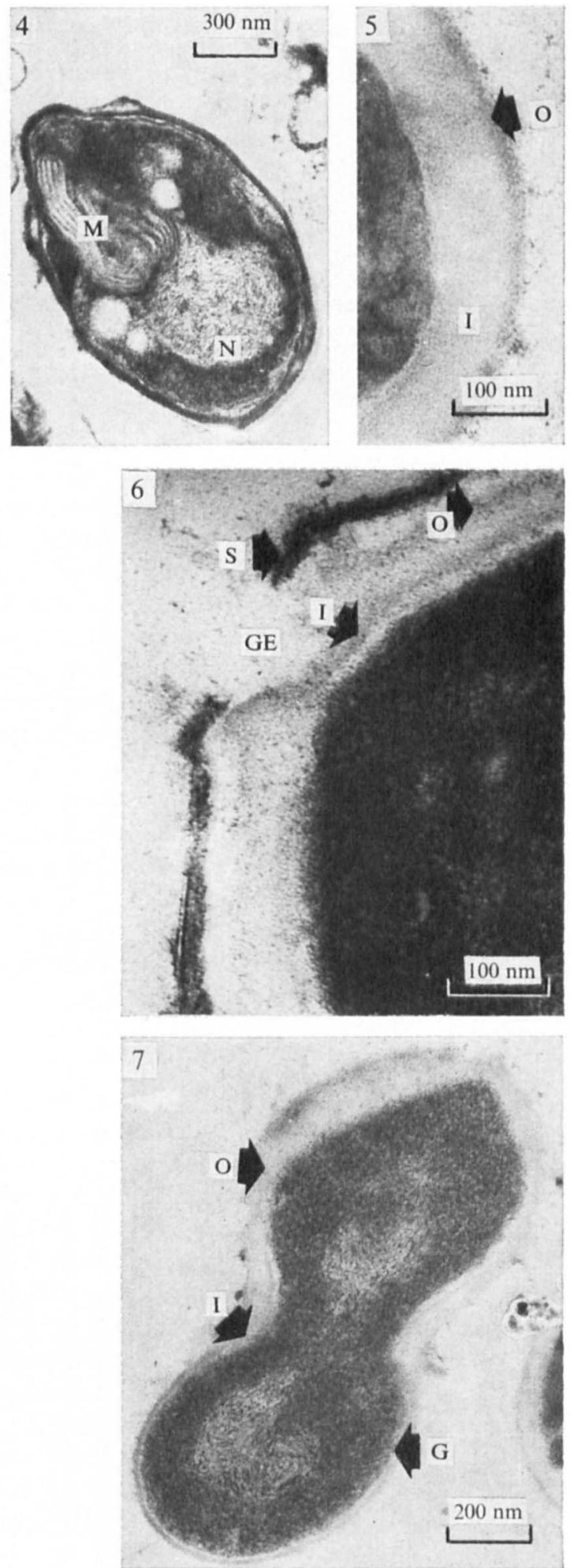


\section{Spore germination in Microbispora rosea}

Mature spores had a diameter of $\mathrm{I} \cdot 0 \mu \mathrm{m}$ with walls $65 \mathrm{~nm}$ in thickness, consisting of several zones of different electron-density (Fig. 8). Study of spore formation indicated that the wall consisted of two major layers: the inner layer ( 23 to $26 \mathrm{~nm}$ ) was derived from the parent hyphal wall whereas the outer one ( 26 to $33 \mathrm{~nm}$ ) was laid down during spore formation. Spore development occurred within a fibrous sheath but only remnants of this persisted (Fig. 9). Nuclear material was prominent in mature spores and sometimes finely granular bodies (possibly storage material) were observed (Fig. 9).

The diameter of spores increased to $\mathrm{I} \cdot 5 \mu \mathrm{m}$ during germination, resulting in a $\mathrm{I} 24 \% \mathrm{in}$ crease in surface area. Swollen spores were bounded by two wall layers, the inner ( 8 to I5 $\mathrm{nm}$ ) being continuous and the outer (20 to $33 \mathrm{~nm}$ ) ruptured (Fig. Io). The calculated value for the thickness of the inner layer was similar to that observed (Table 2), indicating that stretching rather than synthesis of wall material occurred. The outer layer appeared to be inextensible and ruptured to allow swelling of the spore. The inner layer eventually extended to form the germ-tube wall (Fig. I I). The contents of germinated spores were similar to those of dormant ones but lacked the finely granular bodies.

\section{Spore germination in Micromonospora melanosporea}

Mature spores were $0.6 \mu \mathrm{m}$ in diameter with a wall consisting of an outer layer (Io $\mathrm{nm}$ ) and an inner one ( $50 \mathrm{~nm}$ ) (Fig. 12). Localized thickening of the latter was sometimes present, giving the spore an angular shape (Fig. 13). No sheath was present at any stage of spore development. Spores contained nuclear material, ribosomal granules and mesosomes (Fig. 13).

During germination, the spore diameter increased to $\mathrm{I} \cdot 0$ to $\mathrm{I} \cdot 2 \mu \mathrm{m}$, giving an increase of 177 to $307 \%$ in surface area. The thickness of the inner layer of the wall decreased to a value close to that calculated for stretching (Table 2). The outer layer appeared to be relatively inextensible and ruptured during swelling of the spore. The germ-tube wall was formed from the inner layer of the spore wall (Fig. I4), and soon after its emergence, cross walls developed to separate it from the spore. Spherical electron-light areas were common in germinating spores.

\section{Spore germination in Microellobosporia flavea}

Mature spores were slightly ovoid in shape, measuring about $1 \cdot 7 \times 2 \cdot 2 \mu \mathrm{m}$, and partially enclosed in the prominent sheath in which they developed. Their contents were very dense

\section{Streptomyces ostreogriseus}

Fig. 1. Mature spores in sheath (S) with outer (O) and inner zone (I) in walls.

Fig. 2. Swollen germinating spore with remains of sheath (S) and distinct outer (O) and inner (I) wall layers.

Fig. 3. Emergence of germ-tube $(G)$ with rupture of outer layer $(O)$ and continuity of inner layer (I).

Fig. 4. Germinating spore with mesosome (M) and distinct nuclear material (N).

\section{Micropolyspora faeni}

Fig. 5. Wall of mature spore showing indistinct outer (O) and inner zone (I).

Fig. 6. Wall of swollen germinating spore with break in sheath (S) at point of possible germ-tube emergence (GE). Note indistinct outer (O) and inner zone (I).

Fig. 7. Emergence of germ-tube $(G)$ with rupture of outer layer $(\mathrm{O})$ and continuity of inner layer (I). 




\section{Microbispora rosea}

Fig. 8. Wall of mature spore with distinct outer (O) and inner layer (I).

Fig. 9. Mature spore with indistinct sheath (S), nuclear material (N) and granule (G).

Fig. 10. Swollen germinating spore with ruptured outer layer (O) and intact inner layer (I).

Fig. I I. Emergence of germ-tube (G) with rupture of outer layer $(\mathrm{O})$ and continuity of inner layer (I). 

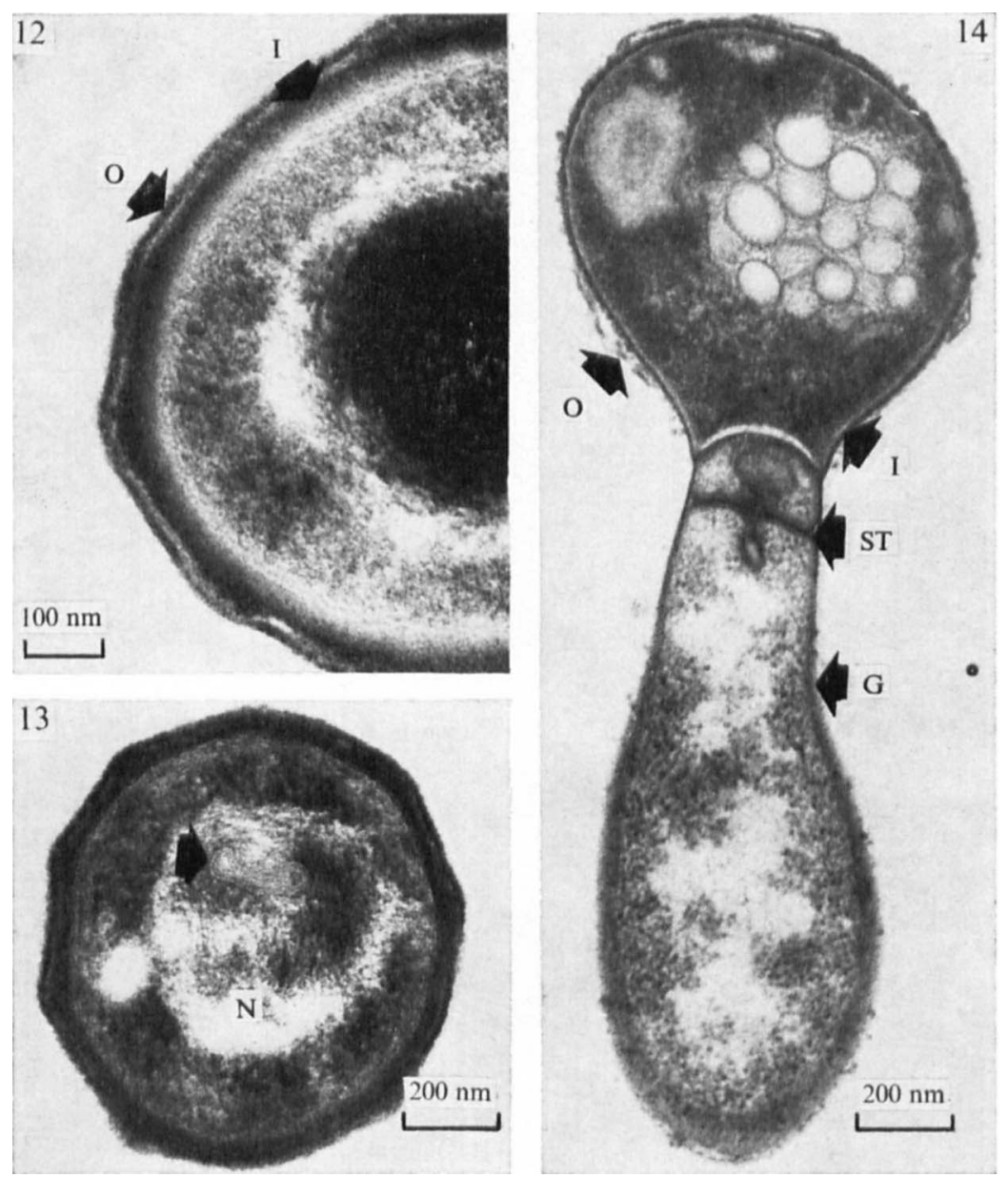

\section{Micromonospora melanosporea}

Fig. I2. Mature spore with angular wall showing outer $(\mathrm{O})$ and inner layers (I).

Fig. 13. Mature spore with mesosome (arrow) and nuclear material (N).

Fig. 14. Germinated spore with germ-tube (G) and septa (ST). Note rupture of outer layer (O) and continuity of inner layer (I).

but sometimes large granules associated with vacuole-like areas were observed. The spore wall was single-layered with a thickness of 50 to $80 \mathrm{~nm}$ (Fig. I5).

The germinating spores increased in size to $\mathrm{r} \cdot 8 \times 3.0 \mu \mathrm{m}$. Unlike the other organisms studied here, the spore wall increased in thickness, reaching 70 to $100 \mathrm{~nm}$ (Table 2). The walls of germinating spores consisted of an outer zone and an inner, more electron-dense zone (Fig. I6). The development of the inner zone ( 15 to $20 \mathrm{~nm}$ ) was responsible for the overall increase in wall thickness. It was this newly synthesized layer which formed the wall of the germ-tube, the other layer rupturing at the point of emergence (Fig. 17). The sheath persisted throughout germination and appeared to extend around the young germ-tube. Germinating spores contained nuclear material and ribosomal particles but lacked the granules and vacuoles present in dormant spores.

The behaviour of the spore wall layers during germination of each organism is summarized in Fig. 18. 

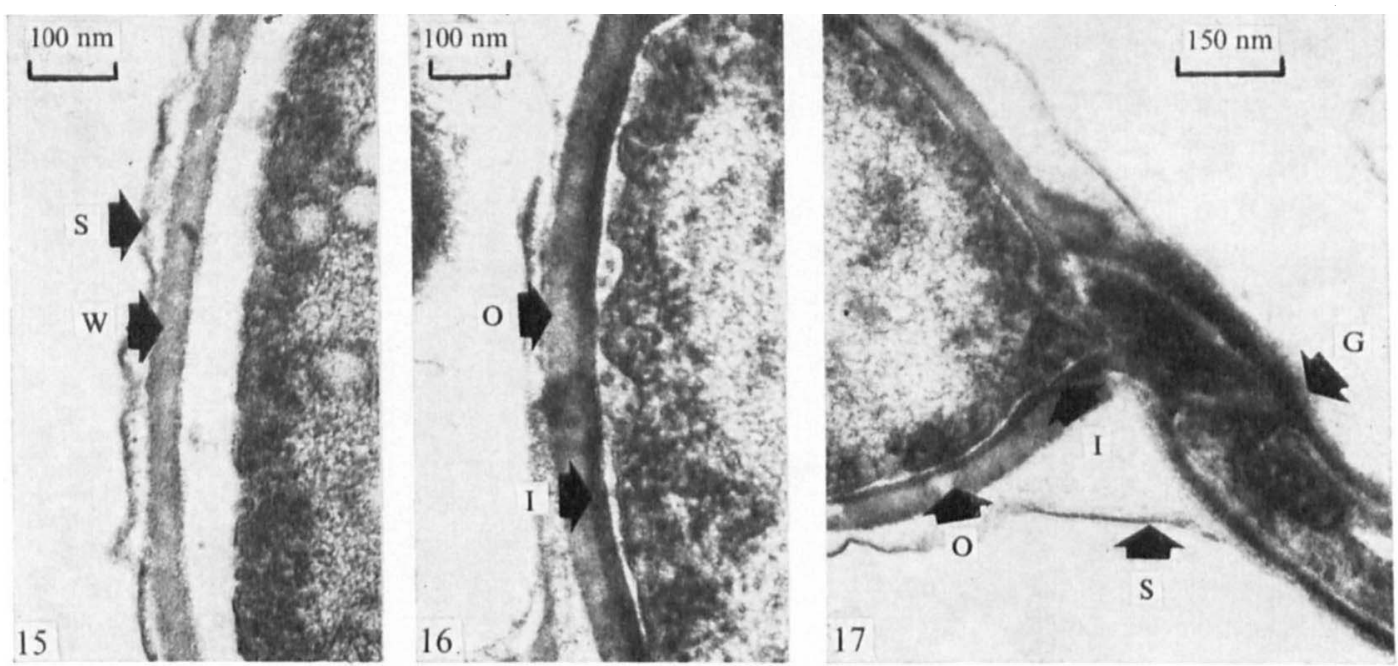

\section{Microellobospora flavea}

Fig. 15. Homogeneous wall (W) of mature spore with distinct sheath (S).

Fig. I6. Wall of swollen germinating spore with outer $(O)$ and inner layer (I).

Fig. I7. Emergence of germ-tube $(G)$ with rupture of outer layer $(O)$ and continuity of inner layer (I). Sheath (S) persists around the germ-tube.

(a)

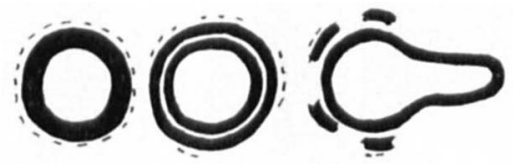

(b)
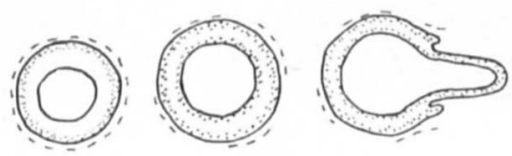

(c)
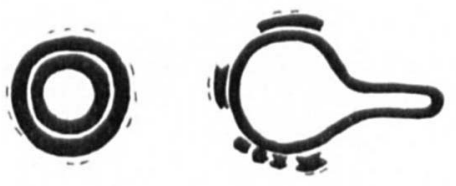

(d)
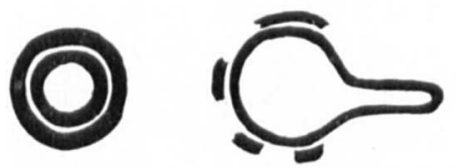

(e)
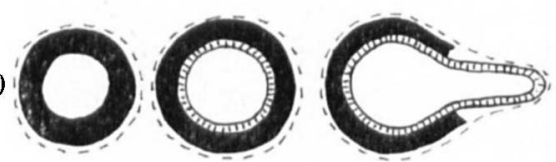

Fig. 18. Stages of germination of (a) Streptomyces ostreogriseus, (b) Micropolyspora faeni, (c) Microbispora rosea, (d) Micromonospora melanosporea, and (e) Microellobosporia flavea. The sheath is represented by the broken line. 


\section{DISCUSSION}

The first indication of germination in all the organisms studied was an increase in the size of the spore, a feature which is common to many fungal spores. Spore contents were sometimes difficult to distinguish in the dormant condition, but nuclear material and ribosomal particles were generally visible in germinating spores. Granules, probably representing storage materials, were sometimes visible in mature spores but disappeared during germination. Mesosomes may have been expected to be present in highly active germinating spores and germ-tubes, but they were common only in Streptomyces ostreogriseus.

The behaviour of spore walls during germination varied and three categories could be recognized: (i) the germ-tube wall arose from a wall layer synthesized de novo during germination within the existing spore wall (e.g. Microellobosporia flavea); (ii) the germ-tube wall arose from an existing inner layer of the spore wall but this did not become distinguishable until germination was initiated (e.g. Micropolyspora faeni, Streptomyces ostreogriseus); (iii) the germ-tube wall al ose from an inner layer of the spore wall which was distinguishable in the dormant spore (e.g. Microbispora rosea, Micromonospora melanosporea). These categories are similar to those recognized in fungi, the main distinction being between germtube walls which arise from newly synthesized material and those arising from material existing in dormant spores (Bartnicki-Garcia, 1968). Previous studies on other Streptomyces species and Thermoactinomyces vulgaris indicate that they fall into categories (ii) and (i) respectively.

There was no apparent correlation between the behaviour of spore wall layers and the chemical composition of the wall. Streptomyces and Microellobosporia have the same wall composition (Lechevalier \& Lechevalier, 1970), but the species studied here behaved differently during germination. On the other hand, Streptomyces spores behaved similarly to those of Micropolyspora, although there are differences in their wall compositions. Similarly, the modes of germination did not seem to have any taxonomic significance. Although it has been suggested that certain groups of fungi have characteristic modes of spore germination (Bartnicki-Garcia, 1968), Khan (1975) concluded that as yet no clear taxonomic significance has been established.

Study of spore germination in five actinomycetes has therefore shown many similarities with fungi. Examination of more actinomycete genera is now required to evaluate the consistency of the patterns of behaviour noted here.

This investigation_was supported by a grant from the Science Research Council.

\section{REFERENCES}

Bartnicki-Garcia, S. (I968). Cell wall chemistry, morphogenesis and taxonomy of fungi. Annual Review of Microbiology 22, 87-108.

Border, D. J. \& TrINCI, A. P. J. (1970). Fine structure of the germination of Aspergillus nidulans conidia. Transactions of British Mycological Society 54, I43-I46.

Bradley, S. G. \& RitzI, D. (I968). Composition and ultrastructure of Streptomyces venezuelae. Journal of Bacteriology 95, 2358-2364.

Dorokhova, L. A., Agre, N. S., Kalakoutskit, L. V. \& Krassilnikov, N. A. (I968). Fine structure of spores in a thermophilic actinomycete, Micromonospora vulgaris. Journal of General and Applied Microbiology 14, 295-303.

Florance, E. R., Denison, W. C. \& Allen, T. C. (1972). Ultrastructure of dormant and germinating conidia of Aspergillus nidulans. Mycologia 64, I I 5-I 23.

Glauert, A. M. \& Hopwood, D. A. (196I). The fine structure of Streptomyces violaceoruber (S. coelicolor). III. The walls of the mycelium and spores. Journal of Biophysical and Biochemical Cytology ro, 505-516. 
Gull, K. \& Trinci, A. P. J. (1971). Fine structure of spore germination in Botrytis cinerea. Journal of General Microbiology 68, 207-220.

HAGEDORN, H. (1960). Elektronenmikroskopische Untersuchungen an Streptomyces griseus (Krainsky), Zentralblatt für Bakteriologie, Parasitenkunde, Infektionskrankheiten und Hygiene (Abteilung II) II3, 234-253.

KalakoutSkir, L. V. \& Agre, N. S. (1973). Endospores of actinomycetes: dormancy and germination. In The Actinomycetales: Characteristics and Practical Importance, pp. 179-195. Edited by G. Sykes and F. A. Skinner. London and New York: Academic Press.

Kalakoutski, L. V. \& Pouzharitskaya, L. M. (I973). The Streptomyces spore: its distinct features and germinal behaviour. In The Actinomycetales: Characteristics and Practical Importance, pp. I55-I 78. Edited by G. Sykes and F. A. Skinner. London and New York: Academic Press.

KHAN, S. R. (1975). Wall structure and germination of spores in Cunninghamella echinulata. Journal of General Microbiology 90, I I 5-I 24.

LACEY, J. \& VINCE, D. A. (I97I). Endospore formation and germination in a new Thermoactinomyces species. In Spore Research I97I, pp. 181-188. Edited by A. N. Barker, G. W. Gould and J. Wolf. London: Academic Press.

Lechevalier, M. P. \& Lechevalier, H. (1970). Chemical composition as a criterion in the classification of aerobic actinomycetes. International Journal of Systematic Bacteriology 20, 435-443.

MACH, F. (1965). Die Substruktur keimender Streptomyces Sporen. Zeitschrift für allgemeine Mikrobiologie 5, 267-273.

REyNolds, E. S. (I963). The use of lead citrate at high $\mathrm{pH}$ as an electron-opaque stain in electron microscopy. Journal of Cell Biology 17, 208-212.

Spurr, A. R. (1969). A low-viscosity epoxy resin embedding medium for electron microscopy. Journal of Ultrastructural Research 26, 3 I-43. 